\title{
Testing Device for Radon Migration Experiments, the Construction and Preliminary Results
}

\author{
M. Bonczyk, ${ }^{1}$ S. Chałupnik, ${ }^{1}$ N. Howaniec, ${ }^{3}$ A. Smoliński, ${ }^{2}$ and M. Wysocka ${ }^{1}$
}

\begin{abstract}
The main goal of the research presented was to design and construct a device, enables estimation of the diffusion time and diffusion length for radon in core samples collected from the geological layers of Upper Silesian Coal Basin (USCB). Another goal will be investigations of the advection of ${ }^{222} \mathrm{Rn}$ with other gases like carbon dioxide or methane, occurring in the Carboniferous strata in USCB. This knowledge will support the precision of the assessment of radon hazard in working environment. Moreover, it should give an answer to some questions, related to the radon migration issues-if the results of measurements of the transport of radon with other gases in the strata could be applied for the prediction of geodynamic phenomena in the mining areas, like tremors and outbursts. The study was focused on the flow measurements of the following gases: radon, carbon dioxide, nitrogen and their mixtures, as the use of methane was excluded due to potential hazard of explosion. In this article results of measurements of diffusive migration are presented: radon itself and simultaneous migration of radon, nitrogen and carbon dioxide. For this purpose a special device was designed and constructed. This device consists of the container for the sample of coal, mineral or rock and two reservoirs-the inlet and outlet one. The gas (e.g. air or carbon dioxide) with radon is introduced into inlet reservoir, while the content of marker gases and radon is monitored in the outlet reservoir. The preliminary experiments were also performed and are presented in this paper. In the literature, there are only rare results of such investigations, while our previous research in USCB region showed some correlation between sudden changes of radon level and geodynamic events. Therefore, the results of the investigations presented in this study are expected to contribute to the improvement of the models of these phenomena. The future work planned will be aimed at investigations of advective flow of radon with various carrier gases.
\end{abstract}

Key words: Radon, diffusion, advection, carbon dioxide, coal basin, experiment.

\section{Introduction}

Radon is the most important source of radiation hazard for people (WHO 2009; Barnet 2012; Killmer 2004). The properties of radon allow it to enter and accumulate in confined spaces, like e.g. tunnels, underground mines and dwellings. The primary source of radon is soil, water and some building materials demonstrating natural radioactivity, which may also affect the indoor radiation exposure.

For this reason, radon concentration and it's exhalation rate is usually determined by measurements of radon emission from soils and different building materials. The radon production depends on the material's porosity, radium concentration and the diffusion coefficient. Many results of experimental researches have been reported for radon transport in soil (Barnet 2012; Prasad et al. 2013; Van der Pal et al. 2001). Another possible approach is the modelling of radon transport; it has been done for instance by Sasaki et al. (2006), Savovic and Djordjevich (2008) and Urosevic and Nikezic (2003) using various media like soil, water, air, etc. The measurements of radon emanation and exhalation are time consuming and require special sample preparation. On the other hand, numerical methods have been applied to find the solution for the diffusion pattern. It can be solved using finite element method (FEM), like presented by Urosevic and Nikezic (2003). It can also be solved using finite differentiate method (FDM), as published by Dimbylow and Wilkinson (1985) and by Savovic and Djordjevich (2008). The FEM method seems to be better solution for three-dimensional geometry, while for the solution of linear (one dimensional) processes the FDM method is more suitable (Savovic and Djordjevich 2008).

Radon is formed in the strata or in building materials. The process of diffusion or co-transport

\footnotetext{
1 Silesian Centre for Environmental Radioactivity, Central Mining Institute, Katowice, Poland. E-mail: mbonczyk@gig.eu

2 Central Mining Institute, Katowice, Poland.

3 Department of Energy Saving and Air Protection, Central Mining Institute, Katowice, Poland.
} 
with other gases through soil and construction materials into the indoor and outdoor atmosphere is known and commonly discussed. The ground permeability is the major parameter, affecting the radon entry and the indoor radon levels in dwellings and workplaces, among them in underground galleries of coal mines. The study of radon diffusion and advective transport through different materials is important for investigations of radon exhalation and for risk assessment. Therefore our investigations are focused on the flow measurements of radon and other gases like carbon dioxide, nitrogen and their mixtures. We undertook attempts to use radon measurements to improve the prediction of geodynamic phenomena in collieries, like outbursts and tremors. In the past, some interesting results were found, especially for outbursts-growing probability of the event was correlated with the decrease of radon concentration in the gas in the strata (Lebecka et al. 1992; Wysocka et al. 1999; Wysocka 2010a, b). This phenomenon is a sudden release of methane and coal into underground workings, very dangerous for miners. As the use of methane in our experiments would be dangerous, it is flammable and potentially explosive, we decided to use inert gases like carbon dioxide or nitrogen as carrier gases.

Our preliminary measurements of the radon diffusion were carried out for different coal samples and other rocks from Carboniferous strata, mostly by passive but also by active techniques (Chałupnik and Wysocka 2003).

It is easier to measure the diffusion transport through different media. For instance, the diffusion coefficient for building materials and soils has been measured by many authors (Chen et al. 2009; Jiránek and Hulka 2000; Rogers 2001; Van der Pal et al. 2001; Kumar and Chauhan 2014). These authors found that the diffusion coefficient in the range from $0.9 \times 10^{-7}$ to $23 \times 10^{-6} \mathrm{~m}^{2} \mathrm{~s}^{-1}$ and calculated the diffusion length of radon from 0.21 to $3.31 \mathrm{~m}$ for following media: cement, soil, sand, and gypsum. The radon diffusion coefficient measured by active technique varied from $1.93 \times 10^{-10}$ to $1.36 \times 10^{-7} \mathrm{~m}^{2} \mathrm{~s}^{-1}$ for samples like paper, polyethylene, marble, granite (Kumar and Chauhan 2014). These authors reported that the radon diffusion coefficient and diffusion length depended mostly on the porosity and density of materials.

Emission of radon from soil surface is known as an exhalation. Theoretical calculations of the exhalation coefficient can be done on the basis of the following equation (Nazaroff and Nero 1988):

$$
\varphi R n=\varepsilon \cdot A_{\text {rad }} \cdot \rho \cdot \lambda \cdot R B
$$

where $\varepsilon$-emanation factor; $\mathrm{A}_{\text {rad }}$-radium content in the soil $\left(\mathrm{Bq} \mathrm{kg}^{-1}\right) ; \rho$ - soil density $\left(\mathrm{kg} \mathrm{m}^{-3}\right) ; \lambda$ radon decay constant $\left(2.1 \times 10^{-6} \mathrm{~s}^{-1}\right)$; RB-the diffusion length (m); $\varphi \mathrm{Rn}$-radon flux $\left(\mathrm{Bq} \mathrm{s}^{-1} \mathrm{~m}^{-2}\right)$.

It is a difficulty to find a site, where only diffusion occurs. Usually, the advective flow of radon with other gases is the most important source of radon.

The advective flow seems to be very important parameter in the areas with complicated geology, additionally affected by coal mining like in the Upper Silesia region in southern Poland (Wysocka 2010a, b). Van der Pal et al. (2001) described their investigations, focused on measurements and model development for diffusive and advective transport of radon through building materials. The main idea of mentioned above authors was to improve the understanding of the radon transport issues through porous media, like construction materials.

A lot of methods have been developed by many researchers to measure radon diffusion coefficient. For instance, an experimental system to estimate radon diffusion coefficients for typical kinds of soil in Japan have been developed (Prasad et al. 2013) and applied for soils with different water saturation levels (0-0.82). The system consisted of a passive-type scintillation cell, soil column, accumulation tank, and radon source. The radon diffusion coefficients variation was from $9.60 \times 10^{-6} \mathrm{~m}^{2} \mathrm{~s}^{-1}$ to $1.27 \times 10^{-7} \mathrm{~m}^{2} \mathrm{~s}^{-1}$ for the loam samples, and was almost constant for a water saturation range of $0-0.4$ and decreased with increasing water saturation from 0.4 to 0.82 .

In our paper the results of diffusion experiments, done by authors with a use of the similar device, developed in the Central Mining Institute, Katowice, Poland are presented. The future work planned will be aimed at investigations of advective flow of radon with various carrier gases. 


\section{Experimental}

\subsection{Radon Diffusion Equations}

To observe the changes of radon concentration as a result of the diffusion, measurements of radon concentration during its migration through a porous medium are required. In this approach, the general model proposed by Sasaki et al. (2006) was employed. Two chambers having different radon concentrations are separated by porous medium, in our case crushed coal samples with the grain size between 0.5 and $1.0 \mathrm{~mm}$. Since the radon is initially present in one chamber only, radon diffusion occurs from one chamber to another. The flow is one directional, as the initial radon concentration in the second chamber is zero. Fick's law describes radon one dimensional flow density $\mathrm{J}$ through the medium (Sasaki et al. 2006):

$$
J=-D \cdot \partial C(x, t) / \partial x
$$

where $\mathrm{J}$ is the radon flux density $\left(\mathrm{Bq} \mathrm{m}^{-2} \mathrm{~s}^{-1}\right)$, D is the diffusion coefficient in the medium $\left(\mathrm{m}^{2} \mathrm{~s}^{-1}\right), \mathrm{C}(\mathrm{x}$, $\mathrm{t})$ is the concentration of the radon $\left(\mathrm{Bq} \mathrm{m}^{-3}\right), \partial C / \partial x$ is the radon gradient $\left(\mathrm{Bq} \mathrm{m}^{-4}\right)$.

The difference equation for radon diffusion is:

$$
\partial C(x, t) / \partial t=D \partial^{2} C(x, t) / \partial^{2} x-\lambda C(x, t)
$$

where $\lambda$ is the decay constant of radon, of the value $2.1 \times 10^{-6} \mathrm{~s}^{-1}$.

The assumption was made that the radon production within the porous medium may be neglected.

\subsection{Test Stand and Methodology}

The experimental device consisted of three cylinders: two of them containing air, each $1.5 \mathrm{~m}$ long, separated by a cylinder $15 \mathrm{~cm}$ long, where grained coal was placed. Radon diffuses from one cylinder with initial radon concentration $\mathrm{C}$, through coal to another cylinder, connected to radon detector (see Fig. 1).

The steel tubing applied in a tests stand was selected on the basis of the pressure and temperature resistance, radon leakproofness as well as market availability and cost competitiveness of the material. The above mentioned properties were important in terms of the planned tests of pressure- and temperature-driven convection in addition to a diffusive flow.

During diffusion the inlet to the detector was sealed, making it impermeable to radon, at the coordinate $\mathrm{x}=\mathrm{B}$, where $\mathrm{B}$ is the thickness of coal layers. When valves were opened, radon started to diffuse from the one cylinder through the coal and continued until the equilibrium was reached.

$$
C(x, t)=0, \quad t=0 ; \quad 0<x<B
$$

Afterwards radon flux increases with time. The radon flux finally reaches a steady state distribution through the coal sample, for stable radon concentration at the input side. It means that the boundary conditions for the Eq. (3) are:

$$
\begin{aligned}
& C(x, t)=C_{0}, \quad x=0 ; \quad t>0 \\
& J=0, \quad x=B ; \quad t>0
\end{aligned}
$$

Radon flux must be continuous through the boundary between the coal and air in the diffusion pipe. Therefore, at $\mathrm{x}=\mathrm{B}$, the following condition $J_{\text {coal }}=J_{\text {air }}$ is taken into account.

The study was focused on the flow measurements of the following gases: radon, carbon dioxide, nitrogen and their mixtures. In this article results of measurements of migration are presented: radon itself and simultaneous migration of radon, nitrogen and carbon dioxide.

The Lucas cells and radon monitor Pylon AB-5 for grab monitoring of radon level were employed (see Fig. 1). The total volume of the Lucas cells, pump and pipes connecting radon detector to the device was taken into calculations as ca. $0.5 \mathrm{~L}$.

For the experiments, the following data was taken into consideration: the radon concentration in the radon chamber was equal $C_{0}=10 \mathrm{kBq} \mathrm{m}^{-3}$. In the diffusion pipe the initial radon concentration was zero. The value $D_{\text {coal }}=5 \times 10^{-3} \mathrm{~cm}^{2} \mathrm{~s}^{-1}$ was used as the radon diffusion coefficient in the powdered coal (Sasaki et al. 2006) and the value for the air $D_{\text {air }}=0.1 \mathrm{~cm}^{2} \mathrm{~s}^{-1}$ was the same as in the simulations of Sasaki et al. (2006). The length of the cylinder with coal was $\mathrm{B}=15 \mathrm{~cm}$. The air was circulated before each sampling, therefore this length was taken into considerations. Our experimental 


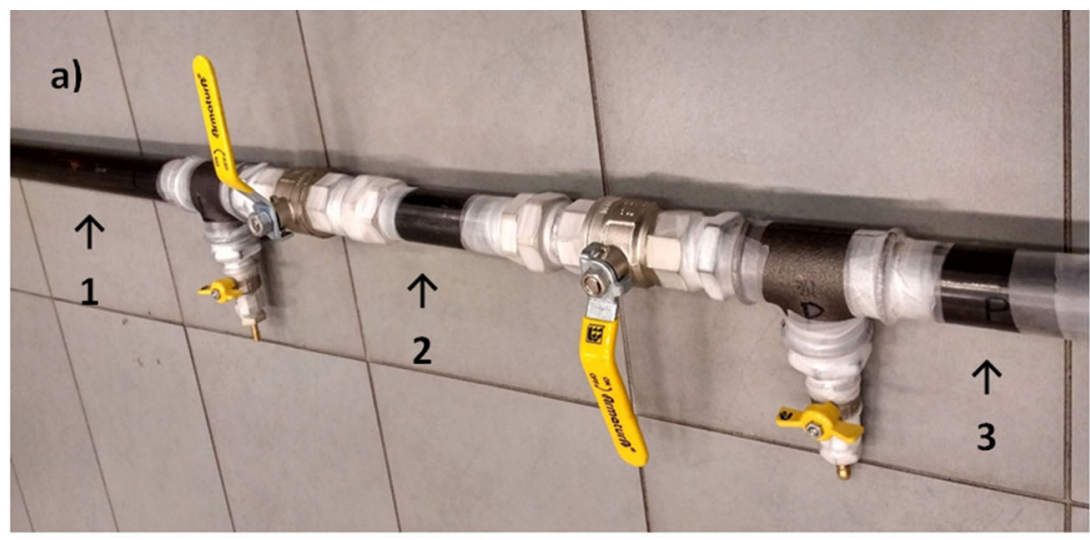

b)

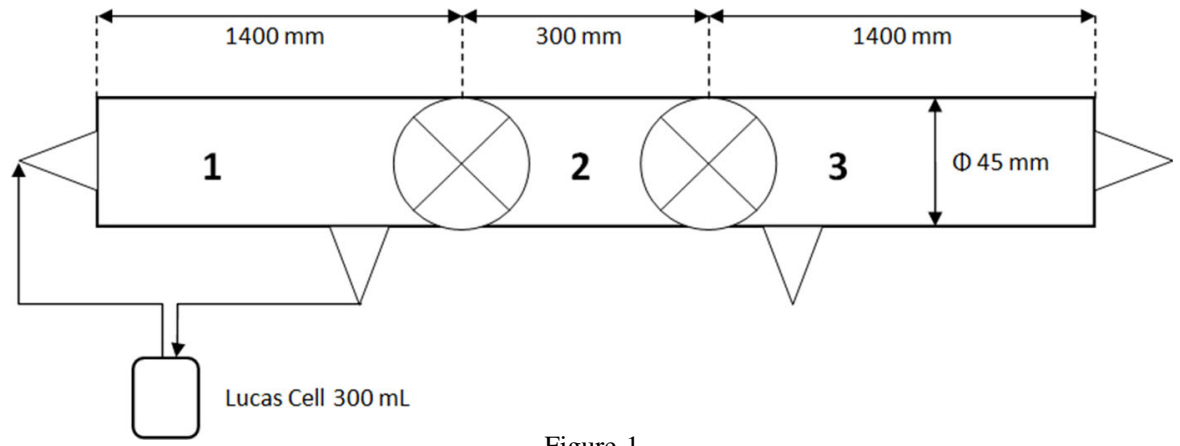

Figure 1

Testing device: a the cylinder (2) with powdered coal between two diffusion pipes (1 and 2) and b schematic diagram of the device

system was sealed at the detector side at coordinate $\mathrm{x}=\mathrm{B}+150(\mathrm{~cm})$, which in total was $165 \mathrm{~cm}$. The radon exhalation from powdered coal has been measured, but due to low radium ${ }^{226} \mathrm{Ra}$ content in coal, not exceeding $10 \mathrm{~Bq} \mathrm{~kg}^{-1}$, the results were low, negligible in comparison with radon concentration in the chamber.

In the first stage of experiments only radon concentrations were measured in air. Therefore two parts of the device were used-sampling cylinder and one diffusion pipe. The sampling cylinder was connected to the radon chamber with the volume of $17 \mathrm{~m}^{3}$. The radon source in form of ceramic sintering with radium of activity $200 \mathrm{kBq}$ was installed in the chamber. The achieved concentration was stable during the experiments. Radon from the chamber was diffusing through the grained coal sample to the diffusion pipe, where radon concentration was measured constantly. Also other parameters like temperature, relative humidity and barometric pressure were measured.

In the second step of the study, the procedure from the first stage was repeated, however the coal sample was not flushed with fresh air. It means that some radon from the first stage remained in the sample.

In the third stage, the diffusion pipe was filled with carbon dioxide. The coal sample was flushed with fresh air before the test. The carbon dioxide flux had opposite direction than the radon. We expected that in this case, the radon flux would be reduced by opposite carbon dioxide flux.

\subsection{Materials}

The coal sample used for test was crushed and sieved to obtain the homogenous fraction of $0.5-1.0 \mathrm{~mm}$. The metal cylinder was filled with the 
grained coal sample and fixed with meshes from both sites of the cylinder in order to avoid the displacement of the sample during the experiments.

\section{Results}

Our initial problem was the lack of the data of the diffusion coefficient for powdered coal. Therefore we weren't able to select or prepare a numerical diffusion model. We applied the approach that at the initial stage of every experiment the diffusion is steady, as the concentration of the radon in the radon chamber and in the device differs a lot. Due to that fact the linear approximation of the radon concentration inside the accumulation pipe should give as the opportunity to calculate the diffusion coefficient.

To check the device and to estimate preliminary results of diffusion through powdered coal samples, three experiments lasting 55-60 h each were performed. Testing system consisted of a radon chamber, a sampling cylinder containing grained coal and a diffusion pipe. Radon concentration in chamber was $10 \mathrm{kBq} \mathrm{m}^{-3}$ (see Fig. 1). Initial concentration of radon in the system was zero. We needed the stable concentration of radon in the chamber during experiment(s). Therefore we applied the diffusive source of radon, from which the continuous emission of radon was going on. Due to that fact, the radon concentration in the chamber was stable, taking into account that the volume of the chamber is $17 \mathrm{~m}^{3}$, while the total volume of the device is few liters only. So the diffusion into the device was not going to change radon concentration in the chamber.

At the very beginning of the experiment the concentration of radon in the coal was zero, the same as in the diffusion pipe. We measured radon exhalation from the powdered coal previously, the result was low and negligible in comparison with radon concentration in the chamber. Subsequently, radon was released from chamber and several times during the experiment sampled into Lucas cell. Finally, $3 \mathrm{~h}$ later radon concentration in the diffusion pipe was measured by means of radon monitor Pylon. Results are shown in Fig. 2.

Results of the experiment showed that initially the increase of the radon concentration was linear, while later the increase was limited by the decay of radon.

Since during the second experiment the coal sample was not flushed with radon-free air, the concentration of radon in the coal was not zero. The objective of this experiment was to check the difference between the diffusion time. Similarly to the first experiment, radon was released from chamber and several times sampled into Lucas cell. After $3 \mathrm{~h}$ radon concentration in diffusion pipe was measured. Results are shown in Fig. 3.

It can be clearly seen, that the initial slope of the increase was steeper than in the first experiment, but

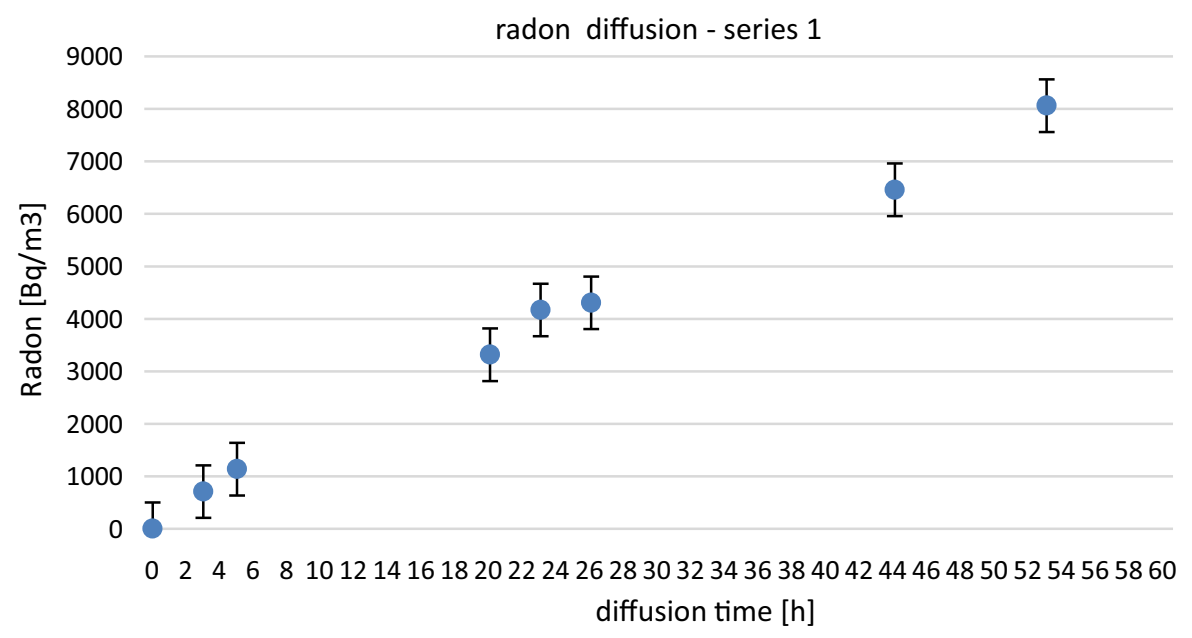

Figure 2

Results of first diffusion experiment 


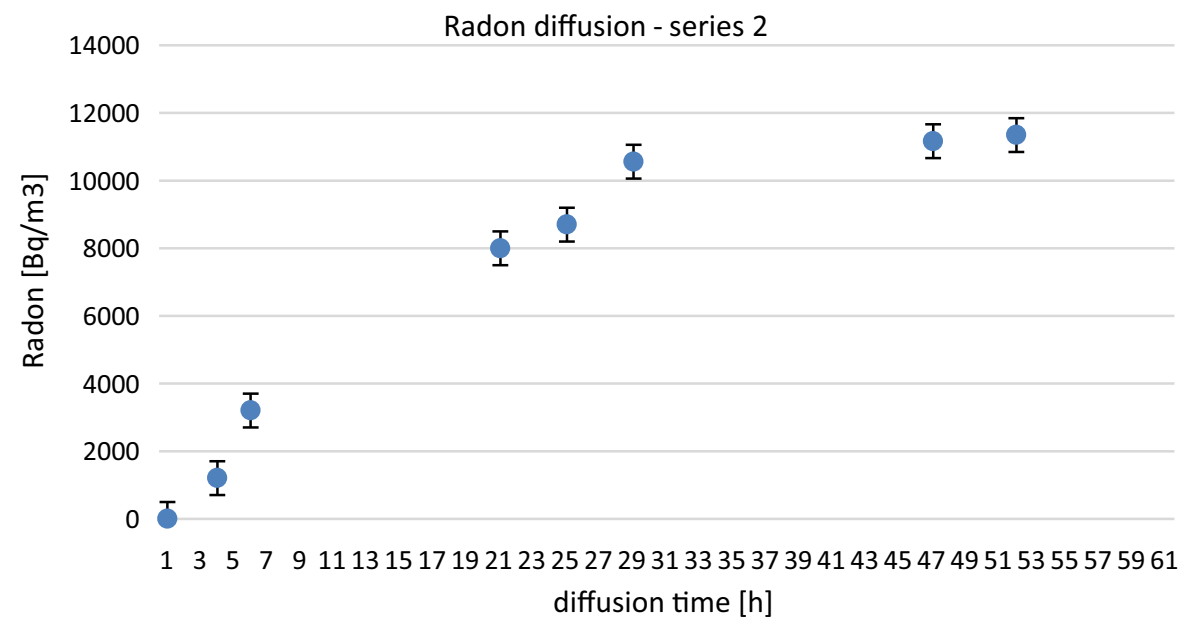

Figure 3

Results of the second diffusion experiment

later the radon concentration growth was limited by the decay of this nuclide. The reason of the faster initial increase in the content of radon in the coal sample was that radon might diffuse into the pipe immediately after connecting to the radon chamber. At the end of the experiment the saturation of radon could be seen, as a result of decrease of the radon gradient between radon chamber and diffusion pipe.

For the third experiment the diffusion pipe was filled with carbon dioxide, to see if there is any difference when the radon diffusion has the opposite direction than the diffusion of the other gas. The initial concentration of radon in the coal was zero. Alike in the first and the second experiment, changes in radon concentration in diffusion pipe were monitored by means of Lucas cells. Results are shown in Fig. 4.

In this case, the initial slope of radon increase was even steeper than in the previous two experiments. Possibly, the migration of carbon dioxide to the radon chamber led to the increase of radon transport in opposite direction-into diffusion pipe.

The diffusion coefficients were calculated basing on the Fick equation (2) and are presented in Table 1.

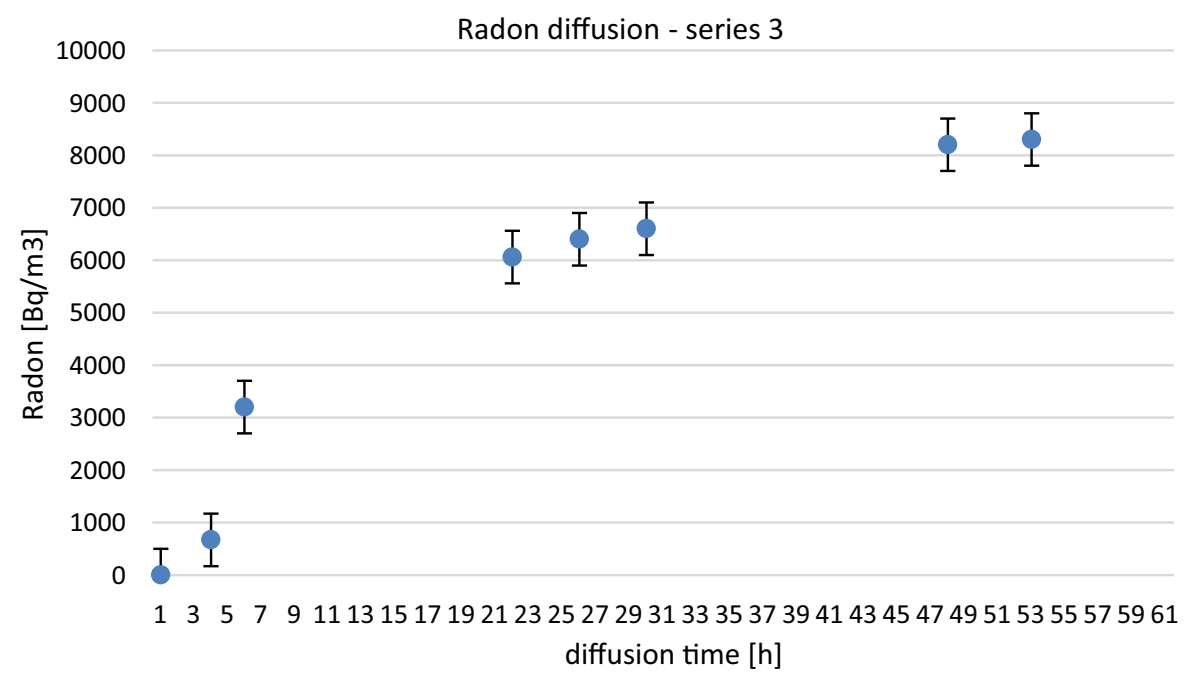

Figure 4

Results of the third diffusion experiment 
Table 1

The calculated diffusion coefficients

\begin{tabular}{ll}
\hline Experiment no. & Diffusion coefficient $\mathrm{D}\left(\mathrm{cm}^{2} \mathrm{~s}^{-1}\right)$ \\
\hline 1 & $0.014 \pm 0.003$ \\
2 & $0.039 \pm 0.008$ \\
3 & $0.038 \pm 0.008$ \\
\hline
\end{tabular}

The preliminary experiments of radon diffusion through crushed coal samples confirmed that the diffusion of radon through such material is fast. The diffusion coefficient estimated from the experiments is roughly one order of magnitude higher than the values estimated for environmental—soil radon transport.

\section{Conclusions}

The main achievement of the presented work was the design and construction of the simple device for measurements of radon diffusion and advective flow through solid samples under laboratory conditions. The device consists of two pipes connected through the sample chamber. Such a construction of the device allows the increase of the pressure and temperature in selected parts of the device so various mechanisms of radon transport (advection, convection) can be investigated.

The preliminary tests performed under various conditions proved an applicability of constructed device in radon transport investigations. More experiments are needed to investigate radon movement through strata.

The preliminary tests were focused on diffusion transport but the future planned work will be aimed at investigations of advective flow of radon with various carrier gases.

Based on the measurements carried out, no cotransport between radon and other gases has been observed in the diffusion experiments.

\section{Acknowledgements}

This work was supported by the Ministry of Science and Higher Education, Poland (11050317).
Open Access This article is distributed under the terms of the Creative Commons Attribution 4.0 International License (http:// creativecommons.org/licenses/by/4.0/), which permits unrestricted use, distribution, and reproduction in any medium, provided you give appropriate credit to the original author(s) and the source, provide a link to the Creative Commons license, and indicate if changes were made.

Publisher's Note Springer Nature remains neutral with regard to jurisdictional claims in published maps and institutional affiliations.

\section{REFERENCES}

Barnet, I. (2012). Indoor radon probability calculated from the Czech soil gas radon data in a grid net for the European Geogenic Radon Map construction: Test of feasibility. Environmental Earth Sciences, 66, 1149-1153.

Chałupnik, S., \& Wysocka, M. (2003). Measurement of radon exhalation from soil: Development of the method and preliminary results. Journal of Mining Science, 39(2), 191-198. https:// doi.org/10.1023/b:JOMI.0000008467.53630.09.

Chen, J. L. J., Schroth, E., Hnatiuk, S., Frenette, E., \& Blain, M. F. (2009). Radon diffusion coefficients of vapour barrier membranes used in Canadian building construction. Radiation and Environmental Biophysics, 48, 153-158. https://doi.org/10.1007/ s00411-009-0212-5.

Dimbylow P. J., \& Wilkinson P. (1985). The numerical solution of the diffusion equation describing the flow of radon through cracks in a concrete slab. Radiation Protection Dosimetry, 11(4)

Jiránek, M., \& Hůlka, J. (2000). Radon diffusion coefficient in radon proof membranes: Determination and applicability for design of radon barriers. International Journal on Architectural Science, 1, 149-159.

Killmer, T. J. (2004). Effects of porosity and permeability on diffusion. Project No S0606, California State Science Fair project summary.

Kumar, A., \& Chauhan, R. P. (2014). Active and passive measurements of radon diffusion coefficient from building construction materials. Environmental Earth Sciences, 72(1), 251-259. https://doi.org/10.1007/s12665-013-2951-5.

Lebecka, J., Wysocka, M., \& Chałupnik, S. (1992). Radon monitoring for the prediction of mine outbursts. In G. Furlan \& L. Tomasino (Eds.), 1991, Proceedings of the second workshop on radon monitoring in radioprotection, environmental and/or earth sciences. Singapore: World Scientific.

Nazaroff, W. W., \& Nero, A. V., Jr. (Eds.). (1988). Radon and its decay products in indoor air. New York: Wiley.

Prasad, G., Ishikawa, T., Hosoda, M., Sorimachi, A., Janik, M., Sahoo, S. K., et al. (2013). Estimation of radon diffusion coefficients in soil using an updated experimental system. Review of Scientific Instruments, 83(9), 093503. https://doi.org/10.1063/1. 4752221.

Rogers, V. C. (2001). Investigation of soil radon diffusion coefficient measurements and methodology. RAE-50344-001-1, URS Corporation, Salt Lake City, UT. 
Sasaki, T., Gunji, Y., \& Okuda, T. (2006). Transient-diffusion measurement of radon in Japanese soils from a mathematical point of view. Journal of Nuclear Science and Technology, 43(7), 806-810. https://doi.org/10.1080/18811248.2006. 9711163.

Savovic, S., \& Djordjevich, A. (2008). Numerical solution of the diffusion equation describing the flow of radon through concrete. Applied Radiation and Isotopes, 66(4), 552-555. https://doi.org/ 10.1016/j.apradiso.2007.08.018.

Urosevic, V., \& Nikezic, D. (2003). Radon transport through concrete and determination of its diffusion coefficient. Radiation Protection Dosimetry, 104(1), 65-70. https://doi.org/10.1093/ $\mathrm{rpd} / \mathrm{ncn} 077$.

Van der Pal, M., Van der Graaf, E. R., De Meijer, R. J., De Wit, M. H., \& Hendriks, N. A. (2001). Experimental set-up for measuring diffusive and advective transport of radon through building materials. Science of the Total Environment, 272, 315-321.

Wysocka, M. (2010a). Investigations of outbursts and tremors in Polish collieries with application of radon measurements. Nukleonika, 55(4), 495-499.

Wysocka, M. (2010b). Radon in the investigations of geo-hazards in Polish collieries. Geofluids, 10(4), 564-570.

Wysocka, M., Skowronek, J., Syrek, B., \& Poręba, G. (1999). Changes of radon concentration in soil gas over some main faults in Upper Silesia Coal Basin. Publications of the Institute of Geophysics, Polish Academy of Sciences, M-22(310), 376-383.

Zeeb, H., \& Shannoun, F. (Eds.) (2009). WHO handbook on indoor radon: A public health perspective. World Helath Organisation. ISBN:9789241547673

(Received June 12, 2018, revised January 29, 2019, accepted January 31, 2019, Published online March 19, 2019) 